\title{
ORGANIC FARMING - THE FUTURE OF THE AGRICULTURAL ECONOMY OF BULGARIA
}

\author{
G. Mitev* \\ Department of Management, Faculty of Economics, Trakia University, Stara Zagora, Bulgaria
}

\begin{abstract}
Organic farming owes its emergence, existence and principles to the nature itself, while the fundamental rule of its practice is to be in harmony with it, without harming it. In fact, it is a new perception of the environment and a new attitude towards its protection, both now and in the future. Organic farming combines the best environmental practices, high biodiversity, the conservation of natural resources and high production standards based on natural substances and processes. It also corresponds to a specific market that responds to specific consumer demands while at the same time it provides public goods that are in terms with environmental protection, animal welfare and rural development.
\end{abstract}

Key words: agroecology, organic farming, biodiversity, organic products.

\section{INTRODUCTION}

Organic farming is an important priority in the agricultural development policy of the Republic of Bulgaria and one of the highlights of the Common Agricultural Policy. The adopted European standards for organic and organic production, for food quality, etc., act as indirect Community regulators for the protection of the environment and ensuring food safety and animal welfare. (1)

The main objective is to encourage farmers to switch to or sustain organic farming, while contributing to: protecting the environment strengthening agro-ecosystems, protecting biodiversity and enabling future generations to benefit from preserved nature; Healthy food production - this form of agriculture responds to the growing needs of consumers as it uses safe and transparent production methods; social impact - creates employment in rural areas and more jobs than conventional agriculture. (MAF, 2014)

Bulgaria is one of the countries in Europe with the highest rates of biodiversity. Conditionally, its territory can be divided into 14 agro-

\footnotetext{
*Correspondence to: Georgi Mitev, PhD, Department of Management, Faculty of Economics, Trakia University, Stara Zagora, Bulgaria Post code: 6000,e-mail: georgimitevvv@abv.bg
}

ecological areas, based on territorial location and climate, productive opportunities and their suitability for cultivation of different plant species according to the bonus score. This agrienvironmental zoning shows the great opportunities of our country for the development of organic production, thanks to natural, climatic and soil diversity, which determine the wide range of products that can be grown organically.

We can positively state that in Bulgaria there are good conditions for the development of organic agriculture. To this we can add the timely synchronization of our agrienvironmental legislation with the European one, which opens the markets of Europe for our organic products.

\section{The essence, principles and rules of organic farming}

1.1 Nature of organic farming

Organic farming is such a production system that does not allow or completely exclude the use of synthetic fertilizers, pesticides, growth regulators and feed additives, and in which the crop and crop residues are relied upon to maintain and improve the soil's nutritional status, manure, green manure and biological plant protection. It is important to realize that organic farming is much more than the exclusion of pesticides and mineral fertilizers. 


\section{MITEV G.}

This is a different manufacturing method, which is imholistic in nature, involving the implementation of many preventative measures. Organic production can only be successful if its overall concept is understood and applied. (2) .The definition of organic farming given by the World Food Organization (FAO) is as follows:

"Organic farming is a holistic production management system that promotes and enhances agro-ecosystem health, including biodiversity, biological circulators and soil biological activity.

Organic farming goals:

(a) Putting in place a sustainable agricultural management system which:

- is compatible with the systems and cycles of nature, preserves and improves the health of soil, water, plants, animals and the balance between them;

biodiversity;

- contributes to a high degree of

- responsibly uses energy and natural resources such as water, soil, organic matter and air;

- compies with high animal welfare standards, in particular meeting the animalspecific behavioral needs of animals;

(b) Production of high quality products;

(c) The production of a wide variety of foods and other agricultural products that meet the consumer demand for goods produced through the application of processes that do not harm the environment, human health, plant and animal health. (3)

\subsection{Organic farming principles}

The documents of the International Federation of Organic Farming (IFOAM) (https://en.wikipedia.org/wiki/Biculture)

outline the basic principles and activities to be followed for organic farming:

- Production of food of high quality and sufficient quantity;

- Harmony with the natural systems without dominating them;

- Maintaining and raising for a long period of soil fertility;

- Using variety of crop rotations saturated with legumes, which include natural and artificial meadows and pastures; fertilizers;

- Not using synthetic pesticides and

- Applying mechanical and thermal weed control methods and alternative means of controlling diseases and pests;

- Maintaining strict accounting of the
- Maintaining a buffer zone between the farm and neighboring conventional farms to prevent accidental contamination.

General principles of organic farming:

Health Principles: Organic agriculture must maintain and enhance the fertility of soil, plants, animals and humans as a whole. Principle of ecology: Organic farming should be based on living ecological systems and cycles, working with them and helping to maintain them. Honesty principle: Organic farming must be built on interrelationships that ensure honesty with regard to the nature of vital relationships. Organic products from third countries of the Common Market are only permitted where they are produced and controlled under the same or equivalent conditions, which eases the import regime.

When purchasing products bearing the EU logo, consumers are assured that:

- at least $95 \%$ of the ingredients of the product, of agricultural origin, are produced by the organic production method;

- the product complies with the requirements of the official control scheme;

- the product comes directly from the manufacturer or processor in a sealed package;

- the product bears the name of the manufacturer, processor or supplier and the name or code of the inspection body.

Organic producers and importers must comply with strict regulatory requirements if they wish to use the EU organic logo. This requirement is monitored at all stages of the productionsupply cycle to assure consumers that they are purchasing organic food produced to European standards that has been subjected to the relevant inspection procedures.

The new procedure allows the EU Commission to exercise oversight and greater control over the import of organic products and the regulation of organic guarantees, and sets the stage for the adoption of EU rules on organic aquaculture and algae.

Cases where they are produced and controlled under the same or equivalent conditions, thereby facilitating the import arrangements.

When purchasing products bearing the EU logo, consumers are assured that:

- at least $95 \%$ of the ingredients of the product, of agricultural origin, are produced by the organic production method;

- the product complies with the requirements of the official control scheme;

farm; 
- the product comes directly from the manufacturer or processor in a sealed package;

- the product bears the name of the manufacturer, processor or supplier and the name or code of the inspection body.

Organic producers and importers must comply with strict regulatory requirements if they wish to use the EU organic logo. This requirement is monitored at all stages of the productionsupply cycle to assure consumers that they are purchasing organic food produced to European standards that has been subjected to the relevant inspection procedures.

The new procedure allows the EU Commission to exercise oversight and greater control over the import of organic products and the regulation of organic guarantees, and sets the stage for the adoption of EU rules on organic aquaculture and algae. (4)

\section{Current state of organic farming in Bulgaria}

Organic agriculture is one of the highlights of the Common Agricultural Policy for the period 2014-2020 and is an important priority for the development of agriculture in the Republic of Bulgaria.

The competent unit, designated in accordance with the organizational rules of the Ministry of Agriculture and Food, which assists the Minister of Agriculture and Food in implementing the quality policy in the field of organic agriculture is the Organic Agriculture Department. The department implements the state policy on supervision and control in the field of organic production and ensures compliance with the requirements of Regulation (EC) No 834/2007. At the national level, organic farming legislation is governed by the Act implementing the Common Agricultural Market Organization of the European Union (in force since 01.01.2007) and Ordinance No.1 of 7 February 2013. for the application of the rules of organic production of plants, animals and aquaculture, plant and animal products, aquaculture and food products, their labeling and control over production and labeling (SG, issue 16 of 2013). Controllers are local and foreign traders within the meaning of the Commercial Law or the legislation of an EU Member State or a State party to the Agreement on the European Economic Area, and have been approved by the Minister for Agriculture and Food. (5)

Encouraging farmers to switch to or maintain organic farming contributes to:
- Environmental protection - strengthens agro-ecosystems, conserves biodiversity and enables future generations to benefit from preserved nature;

- Healthy food production - this form of farming responds to the needs of a growing number of consumers as it uses safe and transparent production methods;

- Social impact - creates employment in rural areas and more jobs than conventional agriculture. (6)

2.1 The state of organic production in Bulgaria in 2019

There are very good prerequisites for the development of organic production in Bulgaria - ecologically preserved areas.

The information on the state of organic production in Bulgaria for 2019 is based on data from the annual reports of officially approved by the Minister of Agriculture and Food Controlling Persons of organic production. The collection of information from the organic production control system shall be within the calendar year.

By the end of 2019, the total number of organic operators registered with the Ministry of Agriculture and Food is 8141 - 600 more than a year earlier. Of these, 7826 are producers, 4 are aquaculture producers, 190 are organic processors and 121 traders (importers, exporters, wholesalers and retailers).

\section{Strengths, Weaknesses, Opportunities and Threats (SWOT)}

Bulgarian organic products are quality and competitive - according to unofficial data, more than $90 \%$ of Bulgarian organic products are exported to EU countries, the USA and Japan.

By size of certified areas for the collection of wild fruits, herbs and mushrooms, Bulgaria ranks second in the EU, and fourth in number of certified bee families. Bulgaria is the largest producer of organic rose oil in the world. National regulation for organic farming, harmonized with the requirements of the European Union. Administrative structures for organic agriculture have been set up at the Ministry of Agriculture and Food: Organic Agriculture Department and the Standing Interagency Consultative Committee on Organic Agriculture. The supervisory and certification system in place guarantees the quality, origin and traceability of organic products and foods. There is very good 
interaction between the MAF (Ministry of Agriculture and Food) and the stakeholders for the development of organic agriculture. Approved by the Minister of Agriculture and Food are the bodies for control and certification of Bulgarian organic products. $\mathrm{He}$ has practical experience in applying organic farming technologies, including by adapting foreign experience. Organic farming is recognized as a tool for sustainable local development. There is support for organic plant breeding and organic beekeeping under the Rural Development Program.

Organic farming contributes simultaneously to the achievement of the objectives of three United Nations conventions: the Convention on Biological Diversity; The United Nations Framework Convention on Climate Change; United Nations Convention to Combat Desertification (European Landscape Convention). Organic farming offers opportunities for additional employment in rural areas of the country. (7).

\subsection{Opportunities}

Bulgaria has exceptional natural resources for the development of organic agriculture. Organic foods are increasingly sought after by consumers. Support for organic production in the European Union is growing, Bulgarian farmers have a chance to join the team of the future by setting a future for production.

Demand for organic products on a global scale has grown steadily in recent years. Global food prices are rising, organic food and beverage prices are rising too. Organic foods are more expensive than conventional foods, with price differences ranging from 30 to $100 \%$, in some cases and more.

A large part of agricultural practice in small farms in Bulgaria is low in the use of mineral fertilizers and pesticides. In animal husbandry, much of the practice is extensive.

Organic cosmetics are of great interest to consumers in the EU, North America and Japan. The traditional essential oils for Bulgaria are already grown organically. With a little effort and know-how Bulgaria can offer a high value added end product.

There are organic funds and programs at EU level.

Organic agriculture uses much more manual labor, which offers a real opportunity for employment in rural areas of the country.
In Bulgaria there is a system of protected areas where it is possible to produce by the methods of organic farming, the local people to profit from the preserved nature, and alternative tourism is already developing, which can use the products of organic agriculture.

There is a good image of Bulgarian agricultural products on the foreign market. Bulgaria has unique products that it can produce (herbs, roses, wild mushrooms, etc.) and for which it is competitive. There are local breeds and varieties that can make organic farming more profitable.

Modern ICT (Information and Communication Technologies) have enormous opportunities for dissemination of information, collaboration, efficient production of products, etc. There is an information network of non-governmental organizations (NGOs) working for environmental protection and sustainable development, which can be used for campaigns to promote organic farming, communications and more.

The terms "bio", "eco", "organic" are already protected by the Bulgarian legislation, and BFSA (Bulgarian Food Safety Agency) successfully controls the observance of the law, "bio mints" are no longer a problem for Bulgarian consumers.

\subsection{Weaknesses}

(a) Weaknesses in the production and processing of organic products:

Lack of tax incentives and other incentive measures for organic farmers. It is difficult for banks to lend to organic production and processing, and the compensatory payments for organic farming under Measure 214 of the RDP are not accepted by banks as a loan guarantee;

Awareness of the biological preparations for plant protection by the employees of BFSA (Bulgarian Food Safety Agency), resulting in ineffective control, sanctions and demotivation of producers. There are no or too few organic processing plants;

Organic producers are excluded from the list of potential employers who may benefit from social programs and employment measures;

There is no information on the quantities of organic products produced in the country;

Inability to consolidate in large enough territories in one place for large organic production;

There is no guarantee for those who start organic farming that there will be no organic farming threatening nearby; 
Internet sales of organic products are not included in the control system.

(b) Weaknesses in science, education, training and consultancy on organic farming:

Small and medium sized organic producers seek advice, training and advice, but if possible free of charge - from colleagues, from companies selling fertilizers and plant protection products, from companies that buy their produce;

There is no system for consultation on organic farming at national level. There is a lack of state financial support to pay for organic farming advisory services;

Insufficient literature in the Bulgarian language in the field of organic agriculture and insufficiently applied research and technologies for organic farming in Bulgaria;

\subsection{Threats}

1. Strong fragmentation of agricultural properties, including for small farms;

2. Lack of a real agricultural land market in Bulgaria;

3. Lack of entrepreneurial culture among Bulgarians, including low organizational culture of Bulgarian farmers;

4. Aging population and migration;

5. Low purchasing power;

6. Minimum limits for agricultural holdings to receive support as EU requirements;

7. Great competition of prepared organic foods from other European countries;

8. Difficult and expensive protection of agricultural land;

9. Depreciated and poor agricultural infrastructure.

\section{CONCLUSION}

The emergence and rapid development of organic farming is a positive example of the role of the market and private initiative that have made this form of farming an integral part and at the same time an instrument for eco-management of agriculture in recent decades. Organic farming is one of the sectors that is developing at a rapid pace in times of crisis, with steadily increasing areas and the number of operators involved in the control system over the last few years.

In Bulgaria, organic production, unlike other agricultural sectors, is growing not at times but at times, and organic farming enjoys a growing interest from producers and consumers. Bulgaria has very good prerequisites for the development of organic agriculture, namely: the desire and awareness of consumers to eat healthy; support for organic producers under the Rural Development Program; the efforts of the
Ministry of Agriculture and Food in partnership with business and non-governmental organizations; ecologically preserved areas; aware of the benefits to the environment and rural areas. Bulgarian bio products are well sold and competitive in the European market, while the internal market can be defined as emerging. Organic agriculture in Bulgaria is in the initial stages of its development, but the potential opportunities for it are very large and it is developing at a rapid pace.

Organic farming is a priority in the future, and thinking about the future is a fundamental characteristic of all people. So, in support of organic farming, we are struggling to bring new meaning to this world in which agriculture should not be in the last row, but to lead it.

\section{REFERENCES}

1. LINKOVA, M. (2013). Scientific Papers of the University of Ruse 2013, Volume 52, Series 5.1, P. 229, P. 229.

2. Nikolova, M. (2009). Retrieved from http://oldweb.ltu.bg/conferences/uur/2009/file s/Presentation\%20Undola_M.Nikolova_09.pd f. Tsvetelina Kabakchieva 65

3. Anna, K. (n.d.). Introduction to Organic Agriculture, Faculty of Plant Protection and Agro-Ecology, Agricultural University Plovdiv.Atanasov and the team. (2014, p. 7,).

4. Yancheva Kh., M. I. (2012,). Handbook of Organic Farming. Sofia: VAP - Vasil Petrov

5. Organic Agriculture - Problems and Prospects, Sofia. National Conference with International Participation, (p. 313,). Sofia, Agricultural Academy, https://www.agriacad.bg/images/novini/Site 2_2\%20(1).pdf.

Cow Anna. (n.d.). Introduction to Organic Agriculture, Faculty of Plant Protection and Agroecology, Agricultural University Plovdiv.

6. Valeva Nellie. (2015, p. 1,2). Development and Prospects of Organic Production in Bulgaria. Bulgarian Chamber of Commerce, Sofia, page 23, https://www.slideshare.net/anialashka/present ation-forum-15072015last.

7. Kostadinova, P., and P. V. (2012, p. 56). Basic Principles and Methods of Organic Agriculture, Agricultural University, Plovdiv, https://uard.bg/files/custom_files/files/docum ents/New\%20knowledge/year1_n3/paper_kos tadinova_y1n3.pdf. New Knowledge, Issue 3. 